\title{
Study on the Temperature Field of Casting Process in ANSYS

$$
\text { Chang } \mathrm{Li}^{1, \mathrm{a}} \text {, Guangbing Zhao }{ }^{1, \mathrm{~b}} \text {, Shuyu Zhang }{ }^{2, \mathrm{c}} \text {, Xing Han }{ }^{1, \mathrm{a}}
$$

${ }^{1}$ School of Mechanical engineering and automation, University of science and technology Liaoning, Anshan Liaoning, 114051, China

\author{
${ }^{2}$ Sinosteel anshan research institute of thermo-energy co., PTD, Anshan Liaoning, 114044, China \\ alichang2323-23@163.com, 'ljfc1888@163.com, 'ljfc888@126.com
}

Keywords: foundry technics; finite element; cast solidification; temperature field

\begin{abstract}
Cast molding is the main manufacture process in foundry, because the most disfigurements occurs in this step, while the foundry itself is a complex non-linear instantaneous transferring heat process, in which it should take the absorbing and releasing potential heat into account. In this paper, it simulates the temperature field changing process of the cast solidification in ANSYS software, gets the temperature field change rule for a typical cast, and analyzed the effect of different foundry technics parameters on composite interface temperature, which will provide numerical bases for optimizing foundry technics parameters in future.
\end{abstract}

\section{Introduction}

Liquid metal forming is to fill liquid metal into molds and cool down to normal temperature, which containing some complex factors influence to cast quality. In traditional casting production, how to formulate the foundry technique is mainly according to experience, evaluating a technics is feasible or not is depended on actual castings verification, which needs massive casting practices to finalize the design, a large number of human power, resources, and finance are needed. Some castings also have a high defective index due to insufficient of process scheme[1].

The essence of the complex liquid metal forming is to solve boundary values of partial differential equation, which is under initial conditions and boundary conditions to solve the Fourier heat transfer equation and elastic mechanics equation, following fluid mechanics, heat transmission mechanics, solid mechanics and etc. In modern times, theoretical researches on liquid metal forming are generally based on definite model and experimental methods. Due to the complex physical field effecting on casting, it is nearly impossible to solve practical problems in production only based on classical theoretical calculation. While with the development and perfect of the computer technologies and numerical calculation methods, it makes possible to solve practical physical process numeric in computer, and the foundry process can be quantitatively described. The essence of numerical simulation technology on casting process is making a geometric finite element discrete on casting molding system. Through numerical calculation to analyze the casting process physical changes characteristics related in the field, such as temperature filed, flow field, stress filed and so on, combined with the form criterion of casting defects to forecast the quality of castings. Numerical simulation of solidification process is very important to optimize the design of foundry technology, predict and control the casting quality and different foundry defect, increase the production efficiency, which can provide reliable theoretical basis for raising and optimizing the foundry technique[2].

\section{The mathematical model and calculation method of solidification process}

The heat transfer in solidification process. The heat transfer in solidification process has three basic modes, that are heat conduction, heat convection and thermal radiation. Because the heat source location is always moving, the latent heat released nonlinearly changing with the solidification process. There exist two interfaces in heat convection, liquid-solid interface and metal casting interface. Single-phase solidification metal macro express as one-dimensional heat transfer, when the liquid-solid interface irregularity or dendritic growth, heat always afferents from liquid to solid phase 
along different direction perpendicular to the interface, micro three-dimensional heat transfer phenomena occurs. In this microscopic area, besides the heat transfer there also has liquid convection. In metal and casting interface, because of the incomplete contact, there exist contact heat resistance, micro convection and radiation heat transfer. Actually, the casting shape, materials diversity and the nonlinearity change of material thermal property make the solidification process to be very complex. In solidification research, it is very important to calculate the temperature filed and solidification speed of dynamic system point, because it directly affects the crystallization, the shrinkage cavity, shrinkage porosity and stress state of the foundry. There are two solving ways, the analysis and the un-analysis, to settle this problem. Analysis must do a series of assumptions that the temperature and solidified layer thickness as a function of time. The un-analysis includes graphical method, electric analogy method and numerical simulation method. When using the mathematics method to analyze the solidification process of heat transfer, both of two methods must follow this equation[3,4].

$$
\frac{\partial}{\partial x}\left(\lambda \frac{\partial T}{\partial x}\right)+\frac{\partial}{\partial y}\left(\lambda \frac{\partial T}{\partial y}\right)+\frac{\partial}{\partial z}\left(\lambda \frac{\partial T}{\partial z}\right)+q=c \rho \frac{\partial T}{\partial t} .
$$

In the equation, $\lambda$ is coefficient of heat conductivity, $T$ is thermodynamic temperature, $q$ is the heat released of unit volume object in unit time, $c$ is specific heat, $\rho$ is density and $t$ is time.

When $\lambda$ is a constant, Eq. 1 can turn into:

$$
\lambda\left(\frac{\partial^{2} T}{\partial x^{2}}+\frac{\partial^{2} T}{\partial y^{2}}+\frac{\partial^{2} T}{\partial z^{2}}\right)+q=c \rho \frac{\partial T}{\partial t}
$$

Establishing the mathematical model of solidification process. Finite difference method divides the casting and casting system into many limited small size elements. Assuming the temperature gradient between two units is constant, establishing algebraic equations on each unit to replace the differential equation based on infinite small unit, and establish the algebraic equation system composed by equations have same unit number[5,7].

The two-dimensional difference equation is

$$
\lambda\left(\frac{\partial^{2} T}{\partial x^{2}}+\frac{\partial^{2} T}{\partial y^{2}}\right)+q=c \rho \frac{\partial T}{\partial t} .
$$

Where, $q$ is the latent heat released during solidification, which only in certain temperature range, otherwise $q=0$, then the difference equation is obtained

$$
\lambda\left(\frac{d y}{d x}\right)+q=c \rho \frac{\partial T}{\partial t}
$$

The release of the latent heat will obviously reduce the casting cooling speed and solidification speed, so accurately reflect the latent heat release law is very important to correctly calculate the temperature distribution of casting.

$$
\rho\left(c-L \frac{\partial f_{s}}{\partial T}\right) \frac{\partial T}{\partial t}=\lambda\left(\frac{\partial^{2} T}{\partial x^{2}}+\frac{\partial^{2} T}{\partial y^{2}}+\frac{\partial^{2} T}{\partial z^{2}}\right) .
$$

Where, $\rho$ is density, $\mathrm{kg} / \mathrm{m}^{3} ; c$ is specific heat $\mathrm{J} /\left(\mathrm{kg} \cdot{ }^{\circ} \mathrm{C}\right) ; L$ is latent heat, $\mathrm{J} / \mathrm{kg} ; f_{s}$ is solid fraction; $T$ is temperature ${ }^{\circ} \mathrm{C} ; t$ is time, $\mathrm{s} ; \lambda$ is coefficient of heat conductivity, $\mathrm{W} / \mathrm{m} \cdot \mathrm{K}$.

Initial conditions and boundary conditions should be defined according to ideal contact or imperfect contact between castings and sand mold, also the setting of atmosphere interface must be considered into[8]. 


\section{The finite-element analysis of temperature field of casting process in ANSYS}

Casting model calculation. Casting solidification process involves phase transition, while the phase change analysis is one of the most powerful functions of ANSYS thermo analysis, so a temperature field analysis is took in it, the measurements shown as Fig.1. Defining the thermal properties parameters of steel casting and sand mold are listed in Table 1 and Table 2, the primary temperature of casting is $1670^{\circ} \mathrm{C}$, the primary temperature of sand mold is $25^{\circ} \mathrm{C}$, the air temperature is $23^{\circ} \mathrm{C}$, the convection coefficient is $65 \mathrm{~W} /\left(\mathrm{m}^{2} \cdot{ }^{\circ} \mathrm{C}\right)$, temperature field distribution and the variation are analyzed. ANSYS considers the latent heat by material enthalpy changing with temperature, Fig. 2 shows the enthalpy change curve during the phase transition process, which is a function of density, specific heat and temperature.

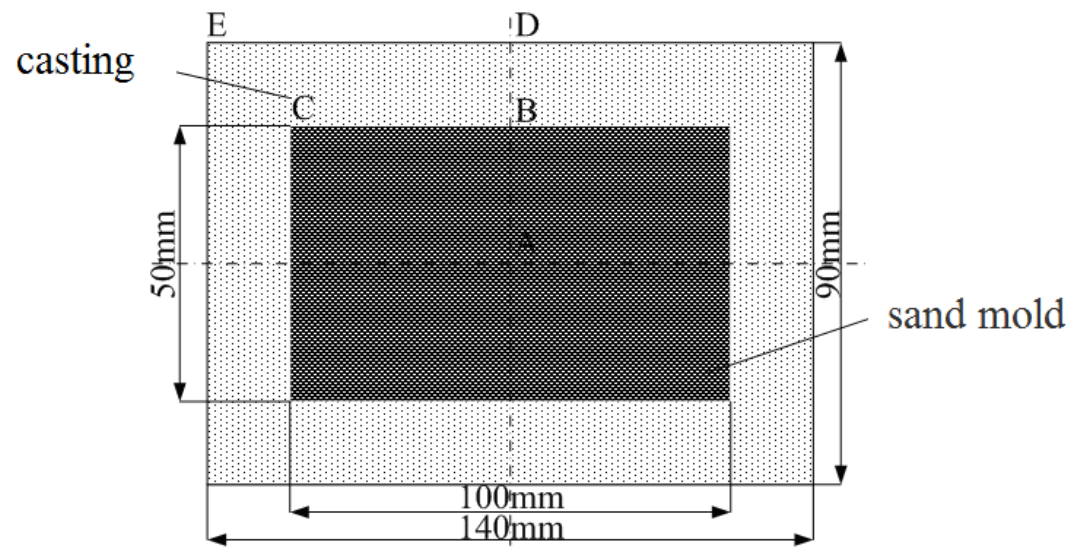

Figure.1 Steel-casting and sand mold cross-section

Table 1 The thermal properties parameters of steel casting

\begin{tabular}{ccc}
\hline temperature ${ }^{\circ} \mathrm{C}$ & coefficient of heat conductivity $\mathrm{W} /\left(\mathrm{m}^{2} \cdot{ }^{\circ} \mathrm{C}\right)$ & enthalpy $\left(\mathrm{J} / \mathrm{m}^{3}\right)$ \\
\hline 25 & 29.8 & 0 \\
1543 & 31.2 & $7.5 \mathrm{E} 9$ \\
1695 & 24.5 & $9.8 \mathrm{E} 9$ \\
1670 & 24.6 & $1.3 \mathrm{E} 10$ \\
\hline
\end{tabular}

Table 2 The thermal properties parameters of sand mold

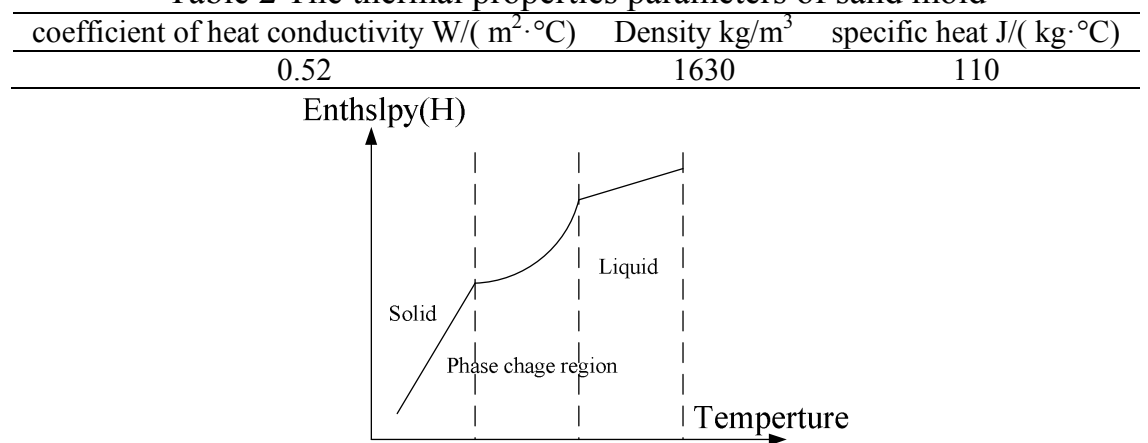

Figure.2 The enthalpy change curve of phase transition process

The finite element analysis of casting process temperature field. It sets the material parameters of the foundry and sand mold according to Table 1 and Table 2 separately, and select PLANE55 unit to mesh the model, then the finite element model of casting process is established shown as Fig.3. 


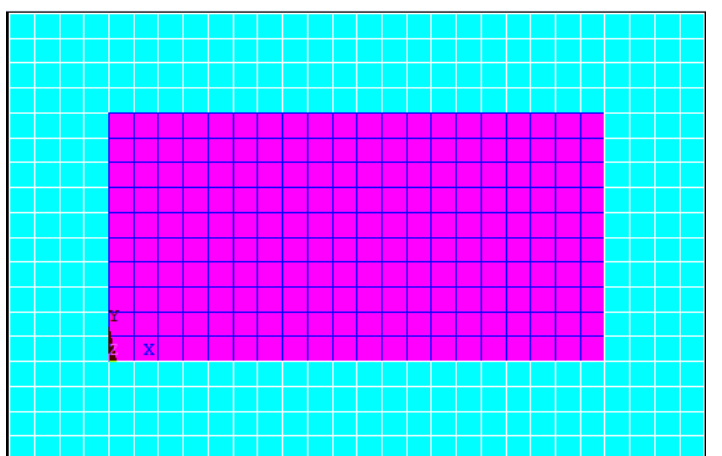

Figure. 3 The casting process finite element model

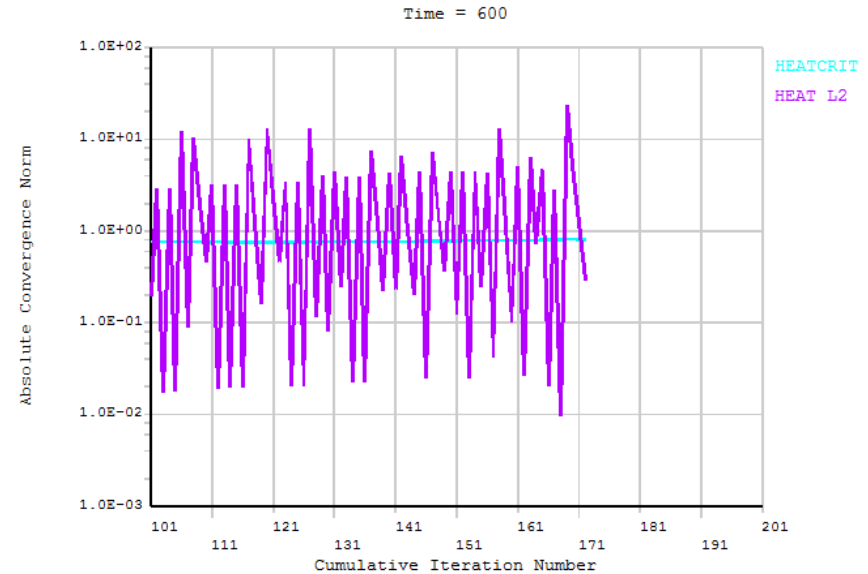

Figure.4 Calculation process convergence curve

Through solving the foundry casting process, casting process temperature field and sand mould temperature field are obtained and shown as Fig.5 and Fig.6. These two figures show the sand mold and casting internal temperature field distribution accurately, it can find that the highest temperature of casting process is $1556^{\circ} \mathrm{C}$, the highest temperature of sand mold is $1543^{\circ} \mathrm{C}$ and the minimum temperature is $133.039^{\circ} \mathrm{C}$ 。

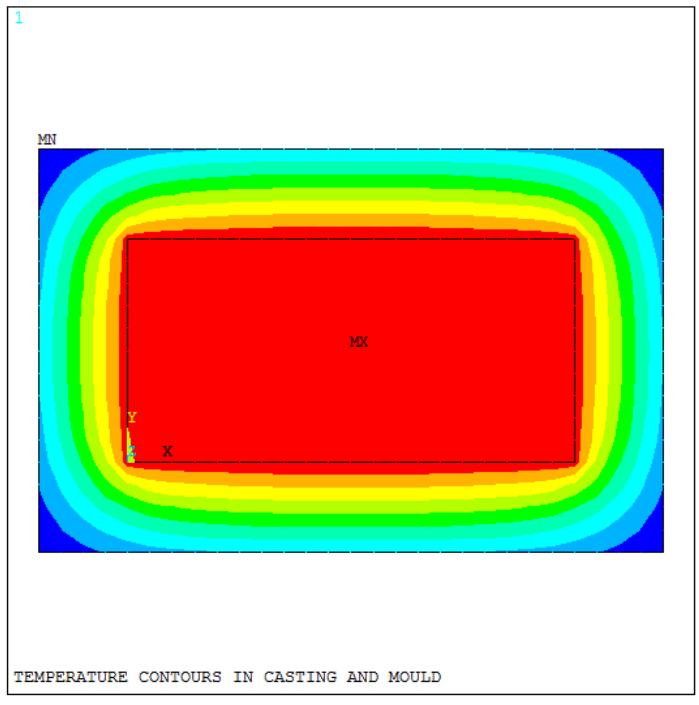

Figure.5 The internal temperature field distribution isoline of the foundry and sand mold

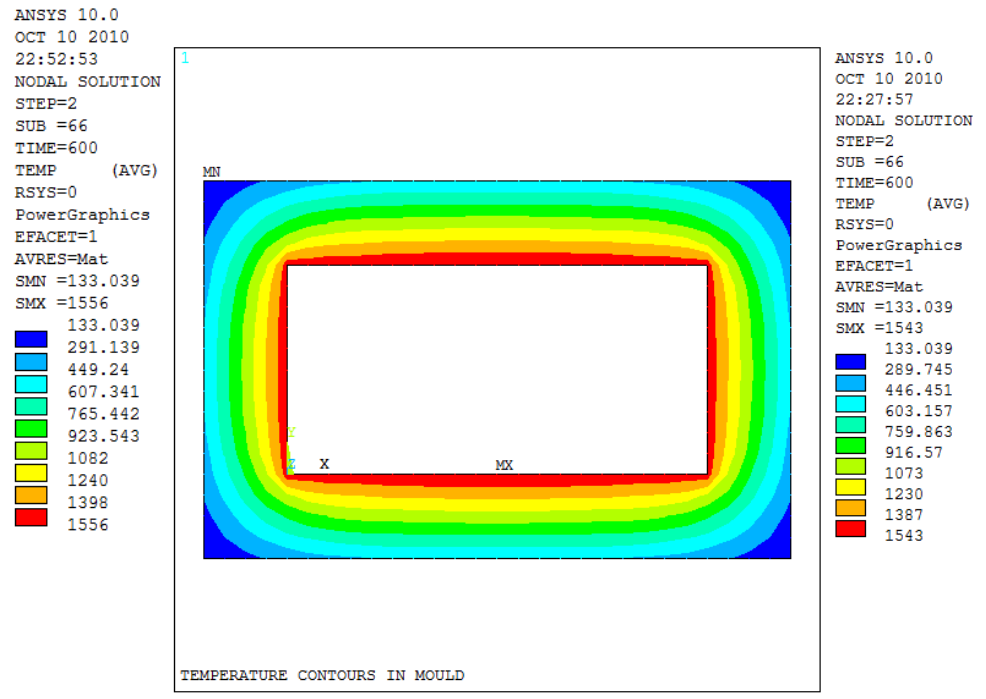

Figure.6 The internal temperature field distribution isoline of the sand mold

Simultaneously, casting temperature changes of points A, C and E are calculated and shown as Fig.7 to Fig.9.

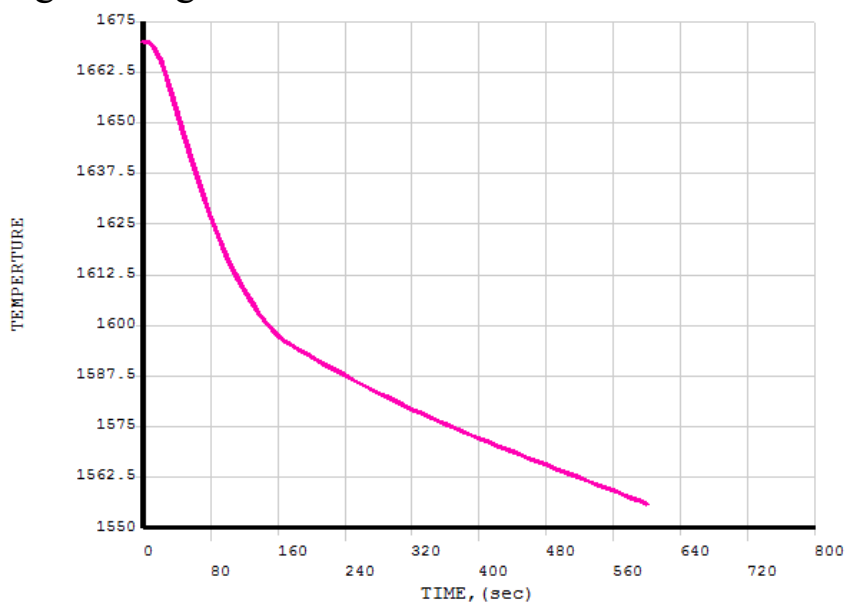

Figure.7 The curve that temperature field changes with time of casting core A

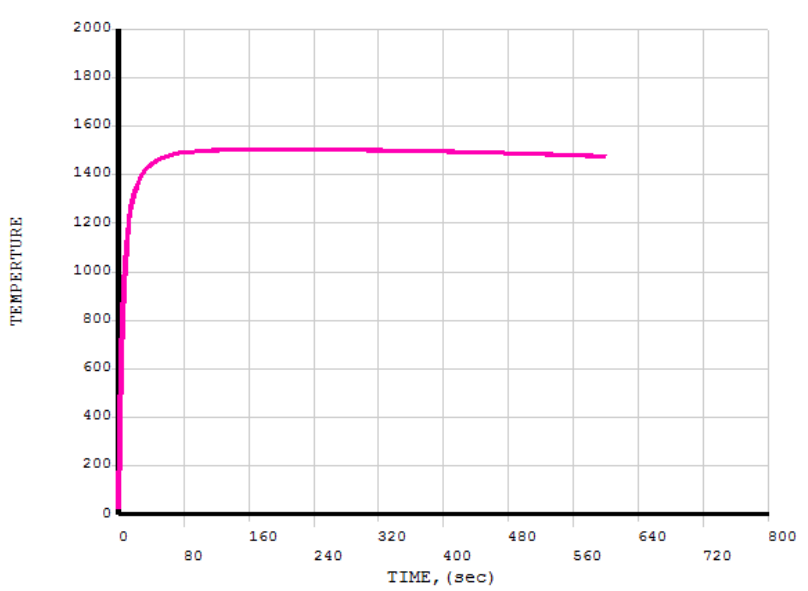

Figure. 8 The curve that temperature field changes with time of casting tip $\mathrm{C}$ 


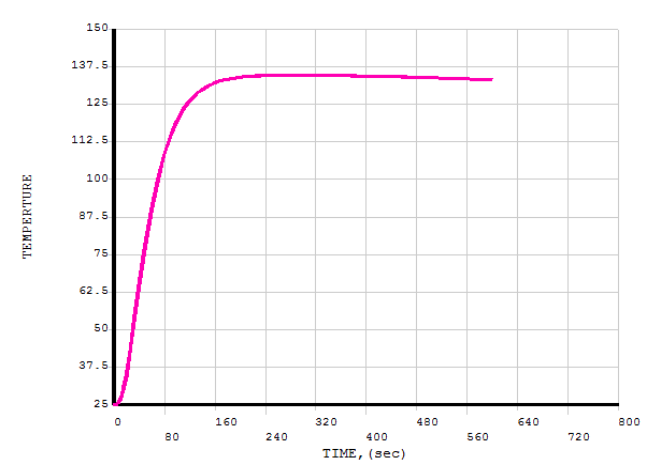

Figure.9 The curve that temperature field changes with time of sand mold tip E

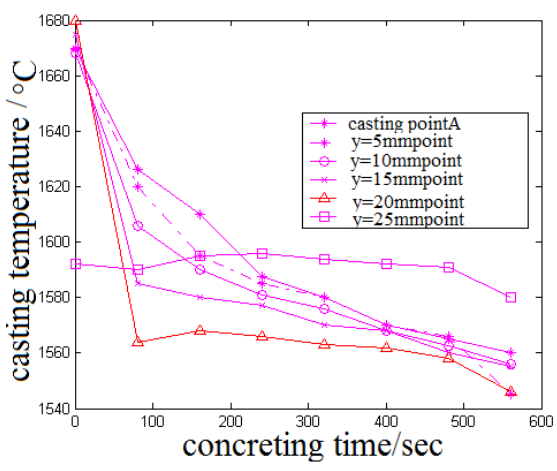

Figure.10 The temperature variation curves of different places of foundry

From the calculation results, it can find that casting core temperature reduced gradually with time, and the temperature of casting tip $\mathrm{C}$ changes with time slowly and declined slightly. While the temperature of sand mold tip E increases transiently, then to slowdown slowly, which meets casting solidification rule in practice, that is to say the calculation conditions setting is feasible. It makes a parametric program to calculate the process of casting temperature field by APDL to create a general macro command file. The change rule of casting process temperature field is got under different working conditions, which provides a basis for optimization design of casting technology. The Fig.10 is the temperature comparison about five points between $\mathrm{D}$ and $\mathrm{B}$ in isometric distant to casting core.

From the figure above, it can find that the temperatures of casting various points reduce gradually with time, while the nearer to casting core the slower of cooling speed.

\section{Summary}

ANSYS software can provide an effective way to the analysis of casting temperature field. In casting production, casting solidification is very important, where most of the casting flaws generated. The numerical simulation of the solidification process is very important to optimize casting technique, forecast and control the casting quality. Casting process is an extremely complex process with high temperature and is dynamic and instantaneous, which is difficult to observe directly, while the traditional casting technique is based on lots of experience and test. Casting numerical simulation is an important method to make casting technique changing from experience test to science guidance, which can forecast the product quality, determine the optimal process scheme, reduce the production cost and shorten the production cycle.

According to the temperature field thermal analysis of casting process, it concludes that the temperature of casting core reduces gradually with time, and the temperature of casting and sand mold ends reduce more slowly.

\section{References}

[1] Lestari W. Damage of Composite Structure: Detection Technique, Dynamic Response and Residual Strength:[Ph D Dissertation].Atlanta: Georgia Institute of Technology,2001.

[2] Zhao Rujia. Mechanical Structure Finite Element Analysis. Xi'an Jiaotong University Press, 1990.

[3] Zhang Yaou. ANSYS7.0 Finite Element Analysis Practical Tutorial. Beijing: Tsinghua University Press, 2003, 1-9.

[4] Wang Jia etc. ANSYS Engineering Analysis Advanced Examples. Press of China Water Conservancy \&Hydroelectricity 2009, 256-237.

[5] Wang Xucheng etc. The Fundamental and Numerical Method of Finite Element Method. Beijing: Tsinghua University Press, 1997, 2-14.

[6] ANSYS, Inc ANSYS Analysis Elements Reverence. Ninth Edition. SAS, IP Inc.1997.

[7] Mou Chenghai. Large Castings Numerical Simulation and Process Optimization[D]. Chongqing: Chongqing University Press, 2007, 12-25.

[8] Zhang Chaohui. ANSYS8.0 thermal analysis tutorial[M]. Beijing: China railway institute publishing house, 2000, 16-27. 